There is no point in seeking to blame anyone for this state of affairs-the press, the public, the profession, or the pharmaceutical industry. The unfortunate truth is that the hostile attitudes of patients' associations and the press, together with the defensive reactions of doctors and drug manufacturers, are combining to produce negative results. Reversing the trends will be a slow process, but it needs to be started. Firstly, doctors must improve the standards of their practical therapeutics; and here the wider use of medical audit procedures could be invaluable. More attention needs to be given to prescribing in both undergraduate and postgraduate education. ${ }^{10}$ Protocol medicine may have undesirable qualities of conveyor-belt uniformity, but there is much to be said in favour of groups of clinicians agreeing a logical, programmed approach to the management of common conditions such as hypertension or peptic ulcer. ${ }^{11}$ We should use fewer drugs (do we really need the 36000 currently available ?) and know more about them. The trend for ever more prescriptions to be written by nurses and receptionists and countersigned by doctors should be reversed. This practice may be useful in easing a heavy work load, but the prescribing doctor, not the patient, should decide whether or not to continue with the same dose of the same drug. The use of ancillary help can only too easily lead to abdication of clinical responsibility. And, most important of all, we need to give much more attention to the recognition and reporting of side effects-the Committee on Safety of Medicines cannot do its job without information from doctors. Almost certainly the side effects of practolol would have been recognised earlier had fuller reports been made to the CSM by the participants in the early trials.

Secondly, patients and the public should be made aware of the inevitability of side effects from powerful modern drugs. Drug safety may be pursued to an unrealistic degree: as Professor Desmond Laurence ${ }^{12}$ said in London last week, "The community must be educated to understand that some risk is quite inevitable and that preventive measures can become excessive." Loss of hair, impotence, and even cancer may be acceptable risks when set against the potential benefits of treatment, but in the past doctors have been reluctant to discuss these possibilities with their patients at the start of treatment. This silence is variously seen as paternalistic, deceitful, arrogant, or compassionate, depending on the individual's point of view; but times have changed and many patients now expect to be taken into their doctors' confidence. Possibly drug side effects could be included in any scheme of no-fault civil liability that may be recommended after Lord Pearson's Royal Commission has reported. ${ }^{13}$

Finally, what about research ? In no way does it seem possible to cut the costs of orthodox drug development to any great extent, for full testing procedures are needed if new drugs are not to carry unacceptable risks. Proposals for nationalisation of a part of the pharmaceutical industry are irrelevant: the problem is world wide and is one of economics and scale and not simply a matter of motivation. Perhaps we shall simply have to accept that the drug explosion is over and that the pace of advance will have to slow until medicine is given more priority in the world economy.

\footnotetext{
1 Wright, P, British Medical fournal, 1975, 1, 595.

2 Brown, $P$, et al, Lancet, 1974, 2, 1477.

3 British Medical fournal, 1975, 2, 577.

4 Petrie, J C, et al, Postgraduate Medical fournal, 1976, 52 (suppl 4), 63.

British Medical fournal, 1976, 1, 413.

6 Petrie, J C, Howie, J G R, and Dumo, D, British Medical Fournal, 1974, 2, 262.

7 Vane, J, speaking at Bicentennial Dedication of the Upjohn Research and Development Centre, Kalamazoo, Michigan; on 18 October 1976.

8 Walshe, J M, Lancet, 1956, 1, 25.
}

9 Walshe, J M, Lancet, 1969, 2, 1401.

${ }^{10}$ Herxheimer, A, and Twycross, R, British Medical fournal, 1976, 1, 1198. 11 British Medical fournal, 1976, 2, 964.

${ }^{12}$ Laurence, D, reported in The Times, 5 November 1976.

${ }^{13}$ Medicolegal, British Medical fournal, 1975, 4, 529.

\section{Epidemiology of anencephalus, spina bifida, and congenital hydrocephalus}

Now that estimation of alpha fetoprotein ${ }^{1}$ in early pregnancy has given such impetus to controlling anencephalus, spina bifida, and congenital hydrocephalus, data collected by the Office of Population Censuses and Surveys ${ }^{2}$ are timely. The survey $^{2}$ by Rogers and Weatherall has shown that the incidence of anencephalus and spina bifida progressively increased for 100 years up to 1942 , when the latter reached a peak of $2 \cdot 1$ deaths per 1000 live births. This was followed by a rapid fall during the next five years, a temporary increase after the war, and then a progressive fall until the end of the 1960s. The numbers of both male and female anencephalics diminished in the 1960s, girls more than boys, and congenital hydrocephalus also decreased in both sexes.

Regional changes in stillborn rates for anencephalus have varied, though everywhere there was a decline in the period 1960-72. In the same way there are regional differences in the proportions of children born with anencephalus and with spina bifida. Wales has equal numbers and the highest rate of both, the north-west has a higher incidence of anencephalus, whereas in the south-west the ratio is reversed. The relation of maternal age to anencephalus and spina bifida also shows regional differences, the young mother being strikingly more likely to have an affected fetus in Wales and the older woman in the north. There is a seasonal variation, too, in both anencephalus and spina bifida, but not for congenital hydrocephalus. The peak conception period for anencephaly is from February to April and for spina bifida from April to June. There is an increased rate in the city as against rural areas and an increased rate in social classes 4 and 5. Rogers and Weatherall have not evaluated the significance of these differences after elimination of the effect on incidence of the age of the mother, a step which only they can do from the primary data.

The analysis of familial incidence and of twins supports the view of Rogers and Morris ${ }^{3}$ that these deformities probably result from environmental influences acting on a genetically susceptible subsection of the population. The local fluctuations in incidence of these deformities still need analysis in. relation to climate, population changes, and chemicals in the environment. Clearly we have much more to learn from epidemiological studies in small areas. Perhaps the most thought-provoking conclusion to be drawn is that fluctuations in the incidence of disease occur quite independently of our medical activities, so putting our scientific conceit into perspective. It is salutary to have this data on anencephalus, which is probably the most consistently registered and one of the most horrifying of all diseases in childhood.

\footnotetext{
1 Rogers, S C, and Weatherall, I A C, Office of Population Censuses and Surveys. Studies on Medical and Population" Subjects, No 32. London, HMSO, 1976.

2 Brock, D J H, and Scrimgeour, J B, Lancet, 1974, 1, 569.

${ }^{3}$ Rogers, S C, and Morris, M, Annals of Human Genetics, 1971, 34, 295.
} 